\title{
Isolation of fastidious mycoplasma from human
}

\section{sources}

\author{
ELLI JANSSON \\ From the Municipal Bacteriological Laboratory, Aurora Hospital, Helsinki, Finland
}

SYNOPSIS A method for the isolation of fastidious mycoplasma from human sources is described.

It is well known that various mycoplasma species have quite different growth requirements. The saprophytic Mycoplasma laidlawii is able to grow without cholesterol. The most fastidious human mycoplasma is $M$. pneumoniae which Chanock, Hayflick, and Barile (1962) succeeded in growing on cell-free media after a modification in the usual pleuropneumonia-like organism (PPLO) media. This was the end of an 18-year history of Eaton agent as a virus.

Because mycoplasma in tissue culture can multiply intracellularly and thus resemble the true parasitism of viruses (Clyde, 1963), the requirement of optimal nutrients on primary isolation is still higher. Tissue culture cell lines are contaminated with mycoplasma in most laboratories. Therefore, cell-free media are to be preferred. Embryonated hens' eggs also may harbour avian mycoplasma, although seldom (Eaton, Farnham, Levinthal, and Scala, 1962).

In our laboratory we have made great efforts for five years to discover a better cell-free medium for fastidious human mycoplasma. The culture method that will be presented here made it possible to isolate mycoplasma from tissue specimens or joint fluid of many patients with rheumatoid arthritis and also from leukaemic bone marrow specimens.

\section{Material and Methods}

\section{MEDIUM}

Bacto brain heart infusion broth was enriched with $20 \%$ pooled inactivated human serum, $2.5 \%$ yeast extract, $1 \%$ glucose, and $20 \mu \mathrm{g}$ per ml DNA. For the human serum pool, serum from 10 blood donors was used. The yeast extract was prepared and stored as described by Chanock et al (1962). DNA was added according to Klieneberger-Nobel Received for publication 18 June 1970.
(1961). Egg yolk pasteurized at $+60^{\circ} \mathrm{C}$ for $50 \mathrm{~min}$ was added in amounts of $0.1 \mathrm{ml}$ per $10 \mathrm{ml}$ enriched medium into broth medium. The medium was thus improved as suggested by Marmion (1967) for antigen production. For solid medium $1 \cdot 1 \%$ agar was used and the egg yolk was omitted. In order to avoid bacterial contamination, 500 units of penicillin per $\mathrm{ml}$ and thallium acetate to a final concentration of $1: 2,000$ were added. The $p \mathrm{H}$ of the medium was adjusted to $\mathbf{7 \cdot 8}$.

\section{CULTIVATION}

The tissue specimens with some broth added were crushed in a mortar. Then a loopful of this mixture or $0.5 \mathrm{ml}$ of undiluted synovial fluid was inoculated into $10 \mathrm{ml}$ of enriched brain-heart infusion broth. This rather large volume of broth was used in order to dilute out possible tissue-bound antibodies. The broth cultures were incubated at $+37^{\circ} \mathrm{C}$ for 20 days and subcultures were made after five, 10, 15, and 20 days by inoculating $0.1 \mathrm{ml}$ on solid medium. Small Petri dishes, $5 \mathrm{~cm}$ in diameter, were used. The cultures on solid media were incubated at $+37^{\circ} \mathrm{C}$ under anaerobic condition for 10 days. In addition, every specimen was inoculated on two blood agar plates for possible bacterial growth and incubated under aerobic and anaerobic conditions for four to five days. Blind passages were done three times by inoculating $0.5 \mathrm{ml}$ of the broth culture into 10 $\mathrm{ml}$ of enriched broth medium and incubating again for 20 days.

\section{MICROSCOPICAL EXAMINATION}

The agar plates were examined for growth under a low-power microscope $(\times 100)$. The suspected growth was stained in situ with drops of $10 \%$ Dienes stain as suggested by Hers (1965). With this exception, the method described by Madoff (1960) for identification of mycoplasma by the stained agar tech- 
nique was followed. An agar block about 1 to 1.5 $\mathrm{cm}^{2}$ was cut off, mounted on a microscope slide with a cover glass, and examined with 100 -fold magnification by a Leitz Orthoplan microscope with the condensor Achr 0.70/L4. Suspected colonies were examined with 1,000-fold magnification and an oil-immersion lens.

\section{Results}

Using the method just described for studies of mycoplasma in rheumatoid arthritis, we isolated in our laboratory a mycoplasma on primary culture and in the first or second passages in several cases (unpublished data). Had we not done blind passages, not so many specimens would have given positive findings. Also a mycoplasma was cultivated from the bone marrow specimens of some patients with leukaemia.

In the primary cultures and in the first passages as few as one to four tiny colonies were observed as a rule in the agar block cut off for examination under the wide-field Orthoplan microscope. In the later passages the number of the colonies increased and many colonies could be seen in the same field.

In the primary culture the colonies were usually tiny, only about $1 / 10$ to $1 / 100$ of the large colony of mycoplasma. Using Dienes stain and an oilimmersion lens the fragile granular structure of the mycoplasma colonies could be seen clearly. Figures 1-6 illustrate the microscopical appearance of some isolates.

Large cells or PPLO cells are often seen in subcultures. Inside these large forms several small cells are formed. When all these are released and broken up, a fragile, pleomorphic granular material remains which stains blue or lilac with Dienes stain. In later passages a fairly abundant growth of fragile granules tends to form on agar resembling a monolayer rather than individual colonies. The growth cycle of the isolates seemed very much like that described by Klieneberger-Nobel (1961).

The isolates did not convert into bacteria when penicillin and thallium acetate were omitted. They required sterol for their growth.

Metabolically, the strains isolated by the method just reported were all glucose- and urea-negative, but some were able to split arginine, especially when tested just after their primary isolation.

\section{Discussion}

The following points seem to be important in trying to isolate fastidious mycoplasma from human sources: (1) a very good culture medium, like the

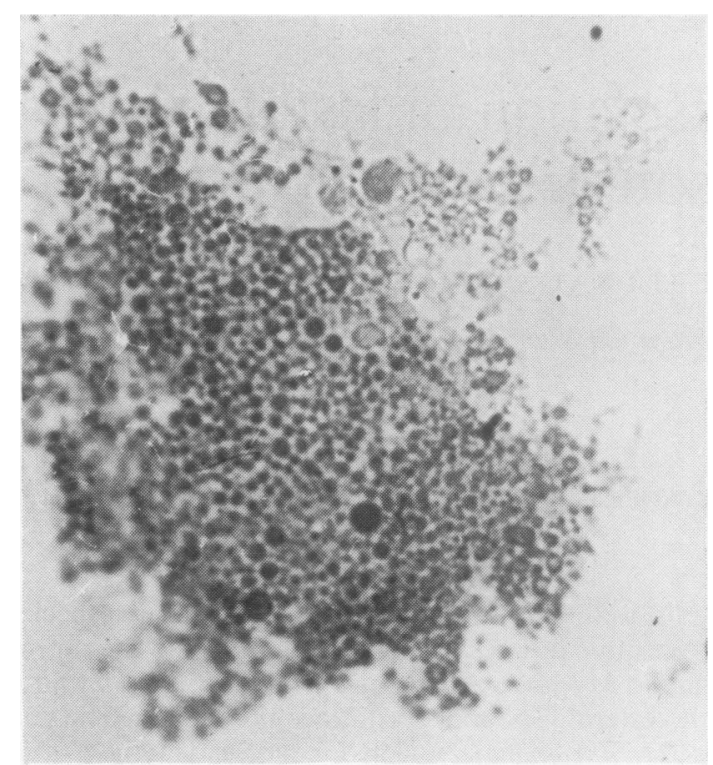

Fig. 1 Strain 152-M, seventh passage, isolated from the joint fluid in rheumatoid arthritis. $\times 1,000$.

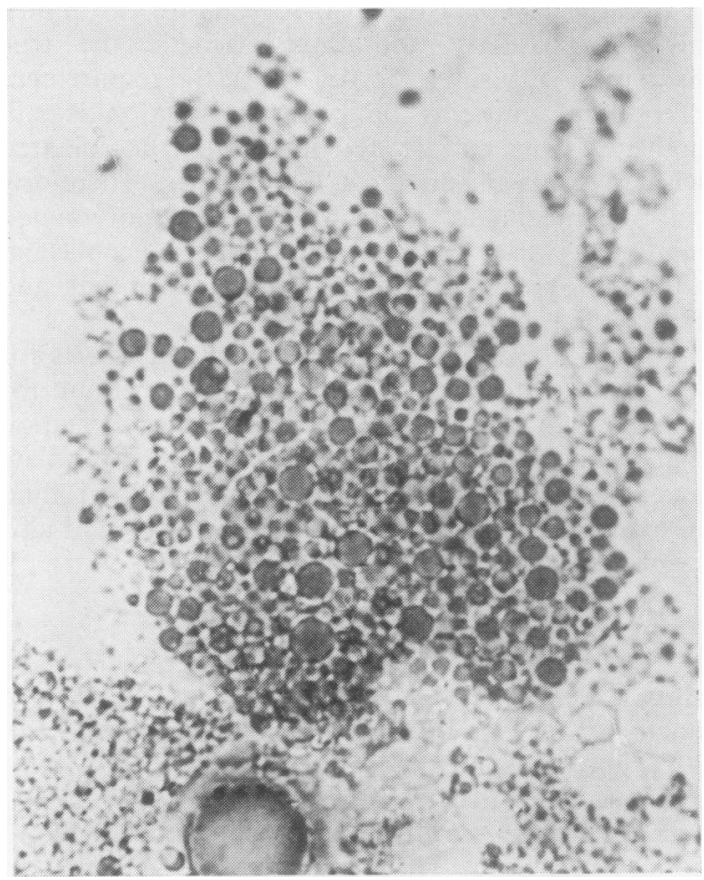

Fig. 2 Strain 194-M, 12th passage, isolated from the joint fluid in rheumatoid arthritis. $\times 1,000$. 


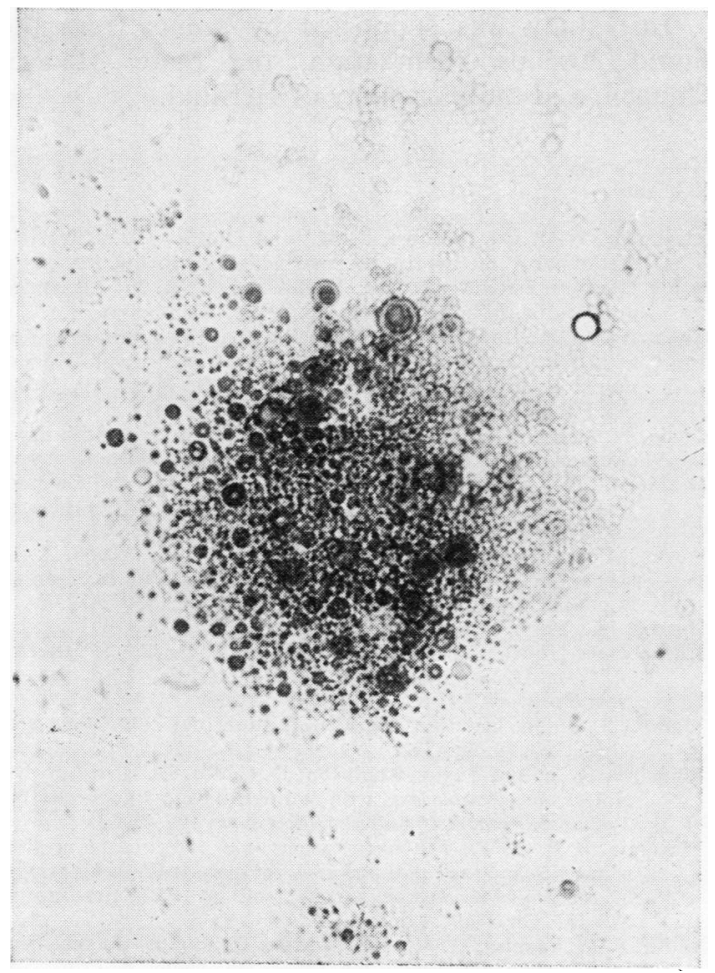

Fig. 3 Strain 261-M, fourth passage, isolated from the joint fluid in acute arthritis. $\times 1,000$.

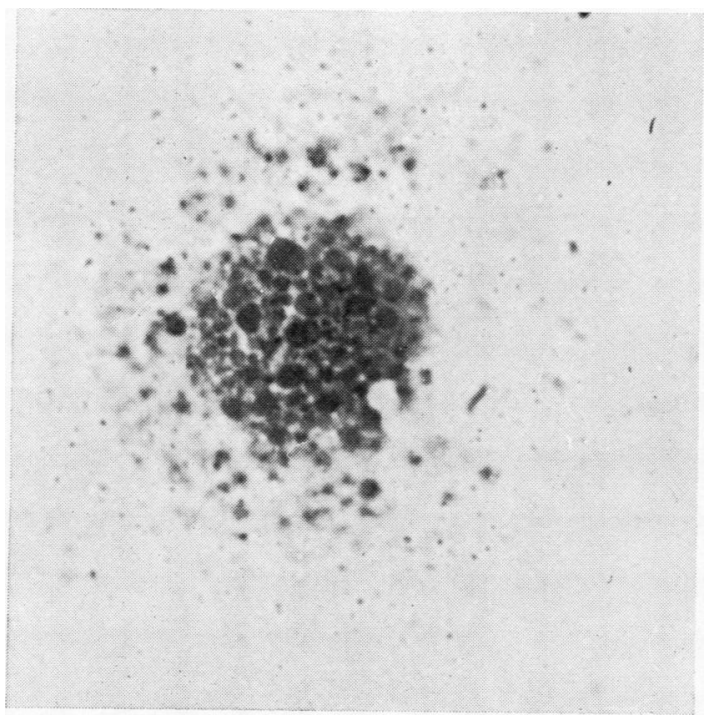

Fig. 5 Strain 299-M, fifth passage, isolated from the bone marrow specimen in a malignant disease. $\times 1,000$.

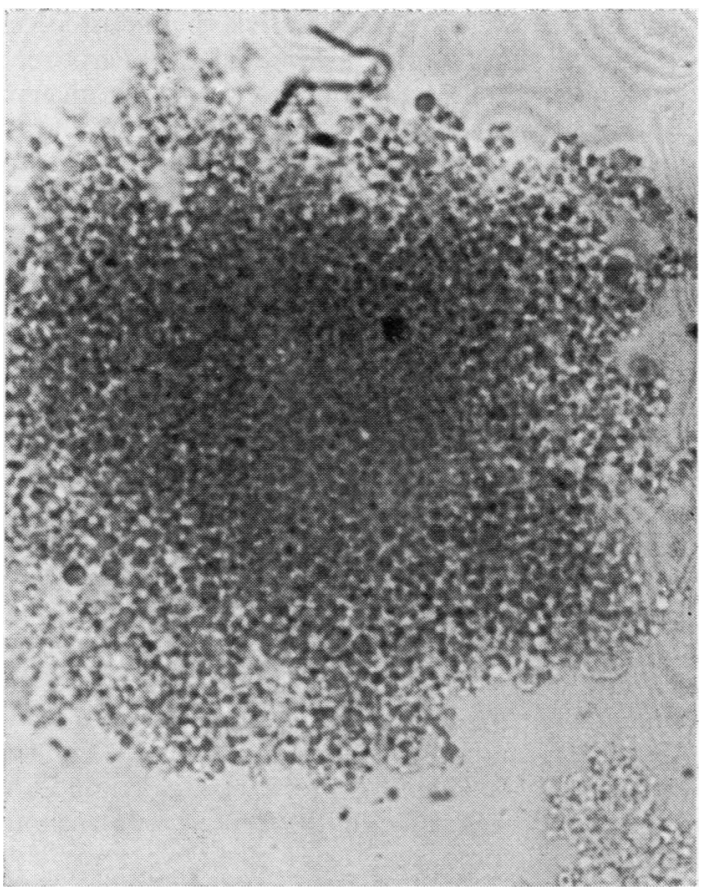

Fig. 4 Strain 288-M, first passage, isolated from the bone marrow specimen in acute leukaemia. $\times 1,000$.

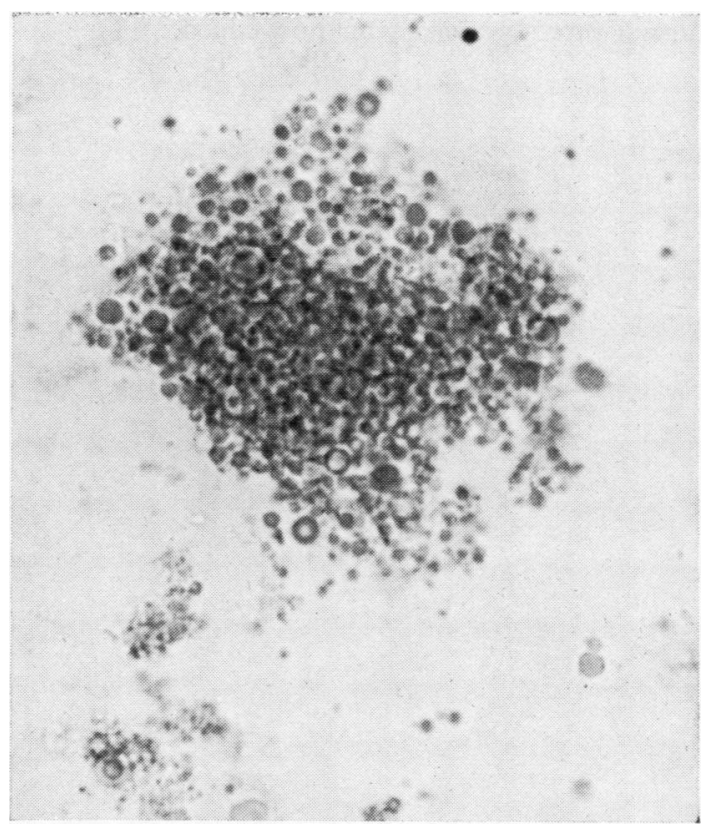

Fig. 6 Strain 277-M, first passage, isolated from a lymph node biopsy specimen in malignant (?) lymphoma. 
one just described; (2) first-class microscopical equipment, preferably a wide-view microscope; (3) long personal experience with mycoplasma.

As regards the culture medium, we found that the diphasic culture medium described by Marmion (1967) was a very good one for isolation of $M$. pneumoniae from throat specimens. Instead of PPLO broth we used brain-heart infusion broth. Thereafter we have used his medium further enriched with pasteurized egg yolk for subcultures of our isolates, and their growth has been good. Also the addition of Hepes buffer (Manchee and TaylorRobinson, 1969) into the culture medium seems to have a favourable effect.

Some investigators (Duthie, Stewart, Alexander, and Dayhoff, 1967; Alexander, Stewart, and Duthie, 1968; Stewart, Alexander, and Duthie, 1969) have found diphtheroids from rheumatoid tissues. When some of our isolates in their first passages were grown in enriched broth without egg yolk, they sometimes showed fragile longer forms. Smith, Alexander, and Duthie (1957) observed the conversion of $M$. hominis type 2 strain Campo into diphtheroid organisms in 1957. We made a similar observation some years ago when we were cultivating a pure culture of the same strain in PPLO broth enriched with rabbit serum and cholesterol but with thallium acetate omitted.

The skilled technical assistance of Miss Sirkka Liisa Tuuri is gratefully acknowledged.
This study was supported by grants from the Sigrid Jusélius Foundation, the State Medical 을 Council, and the University of Helsinki.

\section{References}

Alexander, W. R. M., Stewart, S. M., and Duthie, J. J. R. (1968). Aetiological factors in rheumatoid arthritis. In Rheumatic Diseases, edited by J. J. R. Duthie and W. R. M. Alexander,
pp. 155-164. Edinburgh University Press, Edinburgh.

Chanock, R. M., Hayflick, L., and Barile, M. F. (1962). Growth on artificial medium of an agent associated with atypical pneumonia and its identification as a PPLO. Proc. nat. Acad. Sci. (Wash.), 48, 41-49.

Clyde, W. A., Jr. (1963). Studies on growth of Eaton's agent in tissue culture. Proc. Soc. exp. Biol. (N.Y.), 112, 905-909.

Duthie, J. J. R., Stewart, S. M., Alexander, W. R. M., and Dayhoff, R. E. (1967). Isolation of diphtheroid organisms from rheuma- $N$ toid synovial membrane and fluid. Lancet, 1, 142-143.

Eaton, M. D., Farnham, A. E., Levinthal, J. D., and Scala, A. R. (1962). Cytopathic effect of the atypical pneumonia organism or in cultures of human tissue. J. Bacteriol., 84, 1330-1337.

Hers, J. Ph. (1965). Personal communication.

Klieneberger-Nobel, E. (1962). Pleuropneumonia-like Organisms (PPLO). Mycoplasmataceae. Academic Press, London and New York.

Madoff, S. (1960). Isolation and identification of PPLO. Ann. N.Y. Acad. Sci., 79, 383-392.

Manchee, R. J., and Taylor-Robinson, D. (1969). Enhanced growth of T-strain mycoplasmas with $N$-2-hydroxyethylpiperazine- $\mathrm{N}^{\prime \prime}-2$ 2-ethanesulfonic acid buffer. J. Bacteriol., 100, 78-85.

Marmion, B. P. (1967). The mycoplasmas: new information on their 6 properties and their pathogenicity for man. In Recent Advances in Medical Microbiology, edited by A. P. Waterson, pp. 170-253. Churchill, London.

Smith, P. F., Peoples, D. M., and Morton, H. E. (1957). Conversion of pleuropneumonialike organisms to bacteria. Proc. Soc. exp. Biol. (N.Y.), 96, 550-553.

Stewart, S. M., Alexander, W. R. M., and Duthie, J. J. R. (1969). Isolation of diphtheroid bacilli from synovial membrane and fluid in rheumatoid arthritis. Ann, rheum. Dis., 28, 477-487. 